\title{
Fracture Toughness Characterization of Highly Irradiated Reactor Pressure Vessel Weld from the ATR-2 Experiment
}

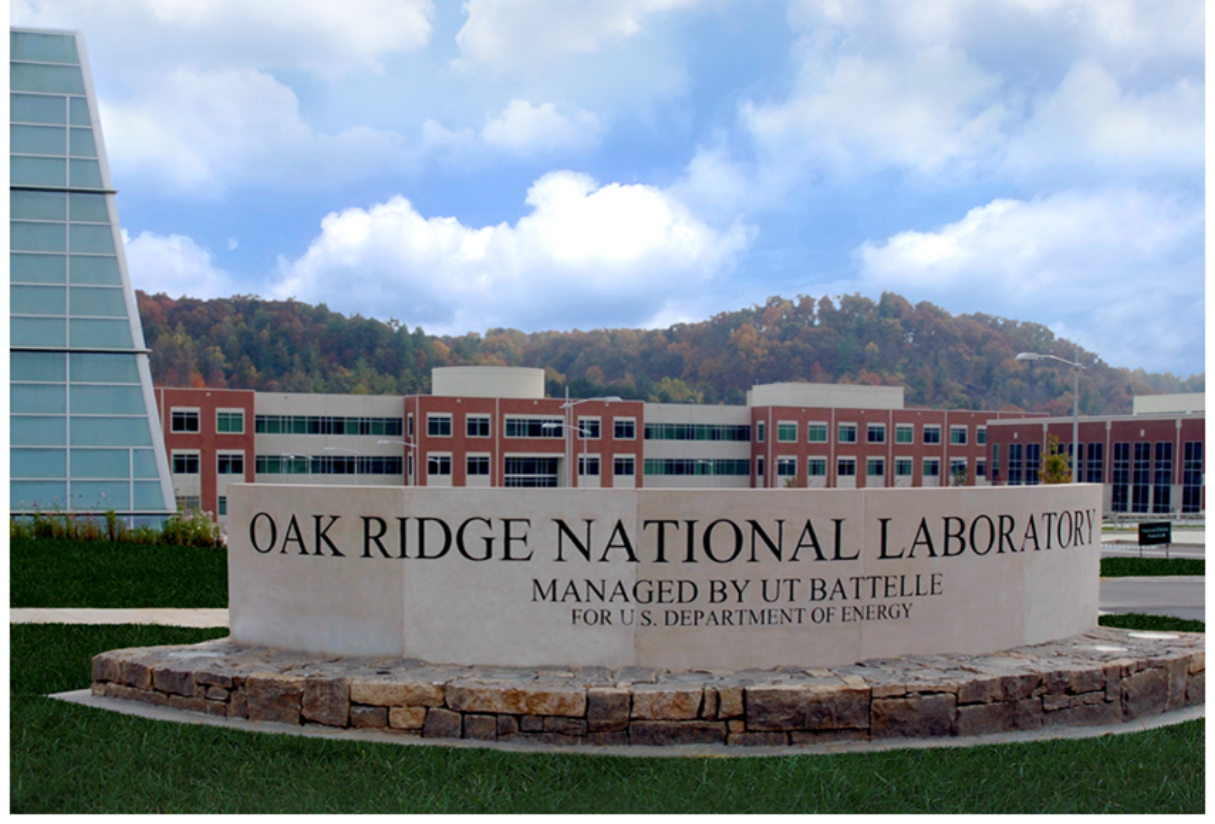

M.A. Sokolov,

$X$. Chen

Oak Ridge National Laboratory

G.R. Odette, University of CaliforniaSanta Barbara

Date: August 2018 


\section{DOCUMENT AVAILABILITY}

Reports produced after January 1, 1996, are generally available free via US Department of Energy (DOE) SciTech Connect.

Website http://www.osti.gov/scitech/

Reports produced before January 1, 1996, may be purchased by members of the public from the following source:

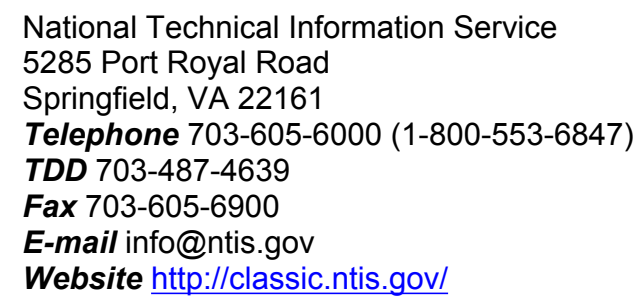

Reports are available to DOE employees, DOE contractors, Energy Technology Data Exchange representatives, and International Nuclear Information System representatives from the following source:

Office of Scientific and Technical Information

PO Box 62

Oak Ridge, TN 37831

Telephone 865-576-8401

Fax 865-576-5728

E-mail reports@osti.gov

Website http://www.osti.gov/contact.html

This report was prepared as an account of work sponsored by an agency of the United States Government. Neither the United States Government nor any agency thereof, nor any of their employees, makes any warranty, express or implied, or assumes any legal liability or responsibility for the accuracy, completeness, or usefulness of any information, apparatus, product, or process disclosed, or represents that its use would not infringe privately owned rights. Reference herein to any specific commercial product, process, or service by trade name, trademark, manufacturer, or otherwise, does not necessarily constitute or imply its endorsement, recommendation, or favoring by the United States Government or any agency thereof. The views and opinions of authors expressed herein do not necessarily state or reflect those of the United States Government or any agency thereof. 
Light Water Reactor Systems

Fracture Toughness Characterization of Highly Irradiated Reactor Pressure Vessel Weld from the ATR-2 Experiment

M.A. Sokolov, X. Chen, and G.R. Odette

Date Published: August 2018

Prepared under the direction of the

U.S. Department of Energy

Office of Nuclear Energy

Light Water Reactor System

Materials Aging and Degradation Pathway

Prepared by

OAK RIDGE NATIONAL LABORATORY

Oak Ridge, TN 37831-6283

managed by

UT-BATTELLE, LLC

for the

US DEPARTMENT OF ENERGY

under contract DE-AC05-00OR22725 


\section{CONTENTS}

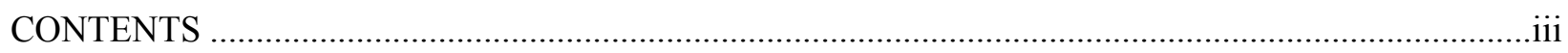

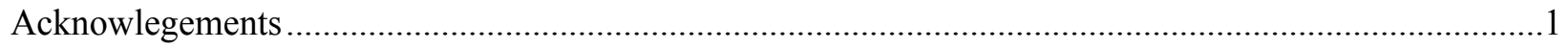

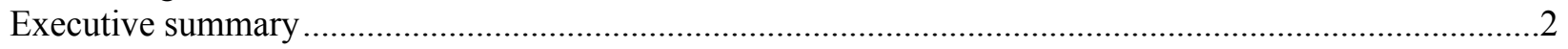

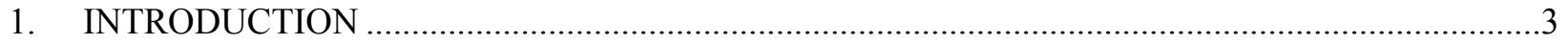

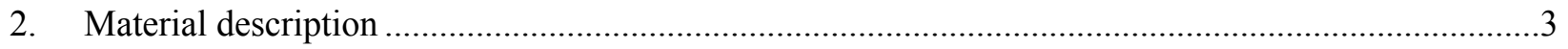

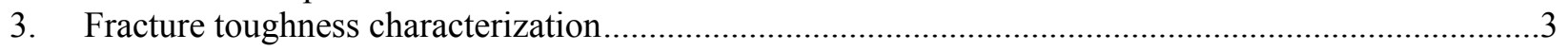

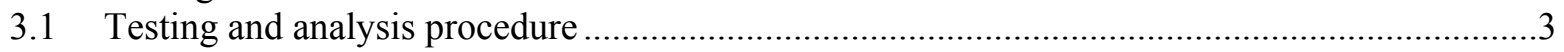

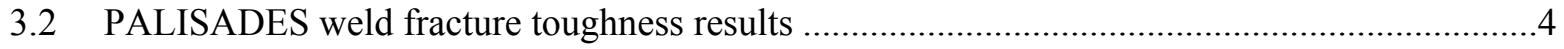

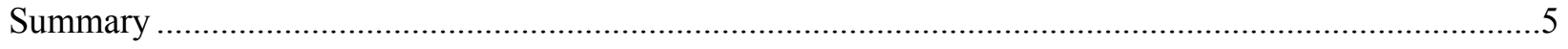

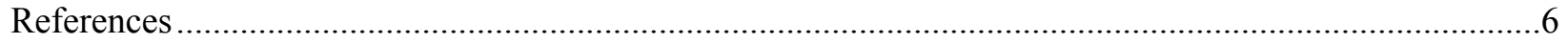




\section{ACKNOWLEGEMENTS}

This research was sponsored by the U.S. Department of Energy, Office of Nuclear Energy, for the Light Water Reactor Systems efforts. The authors extend their appreciation to Dr. Keith Leonard for programmatic support and Dr. R.K. Nanstad and Dr. T.M. Rosseel for technical review. 


\section{EXECUTIVE SUMMARY}

The University of California, Santa Barbara Advanced Test Reactor-2 (UCSB ATR-2) irradiation experiment is designed to generate a new database on a wide variety of irradiated reactor pressure vessel (RPV) steels to fill a critical gap in predicting high fluence embrittlement for extended plant operation up to 80 years. A major focus in this experiment is to characterize the effects of irradiation temperature, neutron flux and fluence, and alloy chemistry on Mn-Ni-Si precipitate (MNSP) evolution, and model how these features impact hardening and embrittlement, manifested as shifts in the ductile-to-brittle transition temperature. As part of these efforts, disk compact (DCT) specimens of three representative materials were included in the ATR-2 experiment to provide direct measurements of the transition fracture toughness shift and, thus, to generate benchmark data to compare current predictive models with actual fracture toughness shifts. In addition, attempts wil be made to use these fracture toughness data to address the potential effect of high dose irradiation on the shape of the fracture toughness Master Curve for highly embrittled RPV material.

This report provides also data for the fracture toughness characterization of the Palisades steam generator weld irradiated in the ATR-2 experiment. This weld was made with the same procedure as that for the RPV beltline weld in the Palisades Nuclear Generating Station and is well known for having high sensitivity to irradiation due to high levels of copper and nickel. 


\section{INTRODUCTION}

The UCSB ATR-2 irradiation experiment is designed to generate a new database on a wide variety of irradiated reactor pressure vessel (RPV) steels to fill a critical gap in predicting high fluence embrittlement for extended plant operation up to 80 years [1-5]. A major focus in this experiment is to characterize the effects of irradiation temperature, neutron flux and fluence, and alloy chemistry on MnNi-Si precipitate (MNSP) evolution, and model how these features impact hardening and embrittlement, manifested as shifts in the ductile-to-brittle transition temperature. As part of these efforts, disk compact $[\mathrm{DC}(\mathrm{T})]$ specimens (DCT in this report) of three representative materials were included in the ATR-2 experiment to have direct measurements of the transition fracture toughness shifts and, thus, to provide benchmark data to compare current predictive models with actual fracture toughness shifts. In addition, attempts were made to use these fracture toughness data to address the potential effect of high dose irradiation on the shape of the fracture toughness Master Curve for highly embrittled RPV material. As part of these efforts, a weld from the Palisades Nuclear Generating Station (PNGS) steam generator has been characterized in the irradiated condition. This report has been prepared in satisfaction of Milestone M2LW-18OR0402013 - "Complete report on fracture toughness evaluation of highly irradiated reactor pressure vessel alloys, that are part of the ATR-2 irradiation experiment."

\section{MATERIAL DESCRIPTION}

The weld material in this experiment was obtained from a PNGS steam generator and identified as PBR. This weld, designated weldment "B" from weld heat 34B009, was provided to UCSB and ORNL by PNGS for research purposes. This weld came from the steam generator and was produced with the same weld wire and heat-treated in the same fashion as the beltline weld of the PNGS RPV. It is well known to have high sensitivity to irradiation due to the relatively large contents of copper and nickel, see Table 1.

Table 1. Chemical composition of PBR weld

\begin{tabular}{|c|c|c|c|c|c|c|c|c|c|c|}
\hline & \multicolumn{10}{|c|}{ Composition, wt. \% } \\
\cline { 2 - 12 } & $\mathrm{Cu}$ & $\mathrm{Ni}$ & $\mathrm{Mn}$ & $\mathrm{Cr}$ & $\mathrm{Mo}$ & $\mathrm{P}$ & $\mathrm{C}$ & $\mathrm{S}$ & $\mathrm{Si}$ & $\mathrm{Fe}$ \\
\hline PBR & 0.2 & 1.2 & 1.3 & 0.04 & 0.54 & 0.01 & 0.11 & 0.017 & 0.18 & balance \\
\hline
\end{tabular}

The PBR weld DCT specimens were irradiated in Cup 6 of the ATR-2 irradiation capsule, at an average temperature of $285^{\circ} \mathrm{C}$ and to an average neutron fluence of $1.37 \times 10^{24} \mathrm{n} / \mathrm{m}^{2}(>1 \mathrm{MeV})$ [6-8]

\section{FRACTURE TOUGHNESS CHARACTERIZATION}

\subsection{Testing and analysis procedure}

The DCT type specimen was selected for this experiment. The diameter of these specimens is $20 \mathrm{~mm}$, which was determined by the diameter of the ATR-2 capsule and the thickness of the specimens is 6.6 $\mathrm{mm}$. The fracture toughness tests were conducted in accordance with the ASTM E 1921 [9] Standard Test Method for Determination of Reference Temperature, $\mathrm{T}_{0}$, for Ferritic Steels in the Transition Range, with a computer-controlled test and data acquisition system. The specimens were fatigue precracked to a ratio of the crack length to specimen width $(\mathrm{a} / \mathrm{W})$ of about 0.5 . The unloading compliance method was used for determining the J-integral. All tests were conducted in strain control, with an outboard clip gage having a central flexural beam that was instrumented with four strain gages in a full-bridge configuration. 
The broken specimens were photographed and the digital images were used to measure final crack lengths.

Values of J-integral at cleavage instability, $\mathrm{J}_{\mathrm{c}}$, were converted to their equivalent values in terms of stress intensity $\mathrm{K}_{\mathrm{Jc}}$ by the following equation [6]:

$$
K_{J c}=\sqrt{J_{c} \frac{E}{1-v^{2}}}
$$

where E is Young's modulus and $v$ is Poisson's ratio.

A $\mathrm{K}_{\mathrm{Jc}}$ datum was considered invalid if this value exceeded the $\mathrm{K}_{\mathrm{Jc}(\mathrm{limit})}$ requirement of the ASTM Standard E $1921[6]$ :

$$
K_{J c(\lim i t)}=\sqrt{\frac{b_{o} \sigma_{Y S}}{30} \cdot \frac{E}{1-v^{2}}}
$$

where $b_{\mathrm{o}}$ is the remaining ligament and $\sigma_{\mathrm{YS}}$ is the yield strength of the material at the test temperature.

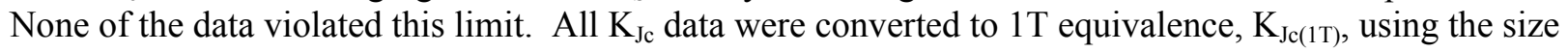
adjustment procedure of ASTM Standard E1921 [9]:

$$
\begin{array}{ll}
K_{J c(1 T)}=20+ & {\left[K_{J c(x)}-20\right] \cdot\left(\frac{B_{x}}{B_{1 T}}\right)^{1 / 4}} \\
\text { where } & \mathrm{K}_{\mathrm{Ic}(\mathrm{x})}=\text { measured } \mathrm{K}_{\mathrm{Jc}} \text { value, } \\
\mathrm{B}_{\mathrm{x}}=\text { gross thickness of test specimen, } \\
\mathrm{B}_{1 \mathrm{~T}}=\text { gross thickness of 1T } \mathrm{C}(\mathrm{T}) \text { specimen. }
\end{array}
$$

The reference fracture toughness transition temperature, $T_{0}$, was determined using the multi-temperature equation from E1921 [9]:

$$
\sum_{i=1}^{N} \delta_{i} \frac{\exp \left[0.019\left(T_{i}-T_{o}\right)\right]}{11+77 \exp \left[0.019\left(T_{i}-T_{o}\right)\right]^{-}} \sum_{i=1}^{N} \frac{\left(K_{J c(i)}-20\right)^{4} \exp \left[0.019\left(T_{i}-T_{o}\right)\right]}{\left\{11+77 \exp \left[0.019\left(T_{i}-T_{o}\right)\right]\right\}^{5}}=0
$$

where $\delta_{\mathrm{i}}=1.0$ if the datum is valid or zero if datum is invalid,

$$
\mathrm{T}_{\mathrm{i}}=\text { test temperature corresponding to } \mathrm{K}_{\mathrm{Jc}(\mathrm{i})} \text {. }
$$

\subsection{PALISADES WELD FRACTURE TOUGHNESS RESULTS}

The fracture toughness reference temperature, $\mathrm{T}_{\mathrm{o}}$, of the Palisades weld in the unirradiatied condition was $-102^{\circ} \mathrm{C}$ as previously reported in [10]. The irradiated fracture toughness data are presented in Table 2. All specimens cleaved; however, two specimens exhibiting ductile tearing prior to cleavage. This work will be continued with two other alloys in the ATR-2 irradiation experiment, CM17 and LP. The results of these two alloys will be published in fiscal year of 2019. The analysis of the PBR weld data yielded a $\mathrm{T}_{\mathrm{o}}=$ $108^{\circ} \mathrm{C}$. Thus, the shift of the transition temperature as result of irradiation is $210^{\circ} \mathrm{C}$. Figure 1 presents unirradiated and irradiated fracture toughness data for the PBR weld and master curves in both unirradiated and irradiated conditions. 
Table 2. Fracture toughness data of PBR weld

\begin{tabular}{|l|l|l|l|l|}
\hline $\begin{array}{l}\text { Specimen } \\
\text { ID }\end{array}$ & $\begin{array}{l}\text { Temperature, } \\
{ }^{\circ} \mathrm{C}\end{array}$ & $\begin{array}{l}\text { Measured } \\
\mathrm{K}_{\mathrm{Ic}}, \mathrm{MPa} \sqrt{\mathrm{m}}\end{array}$ & $\begin{array}{l}\text { 1T-adjusted } \\
\mathrm{K}_{\mathrm{Ic}}, \mathrm{MPa} \sqrt{\mathrm{m}}\end{array}$ & $\Delta \mathrm{a}, \mathrm{mm}$ \\
\hline PBR-7 & 75 & 85.6 & 66.84 & \\
\hline PBR-9 & 90 & 93.6 & 72.55 & \\
\hline PBR-15 & 75 & 77 & 60.69 & \\
\hline PBR-16 & 88 & 59.6 & 48.27 & \\
\hline PBR-17 & 23 & 44.6 & 37.56 & \\
\hline PBR-18 & 80 & 99.6 & 76.83 & \\
\hline PBR-20 & 83 & 80.0 & 62.84 & \\
\hline PBR-27 & 50 & 85.7 & 66.91 & \\
\hline PBR-10 & 94 & 147.8 & 111.24 & 0.30 \\
\hline PBR-29 & 90 & 120.4 & 91.68 & 0.97 \\
\hline
\end{tabular}

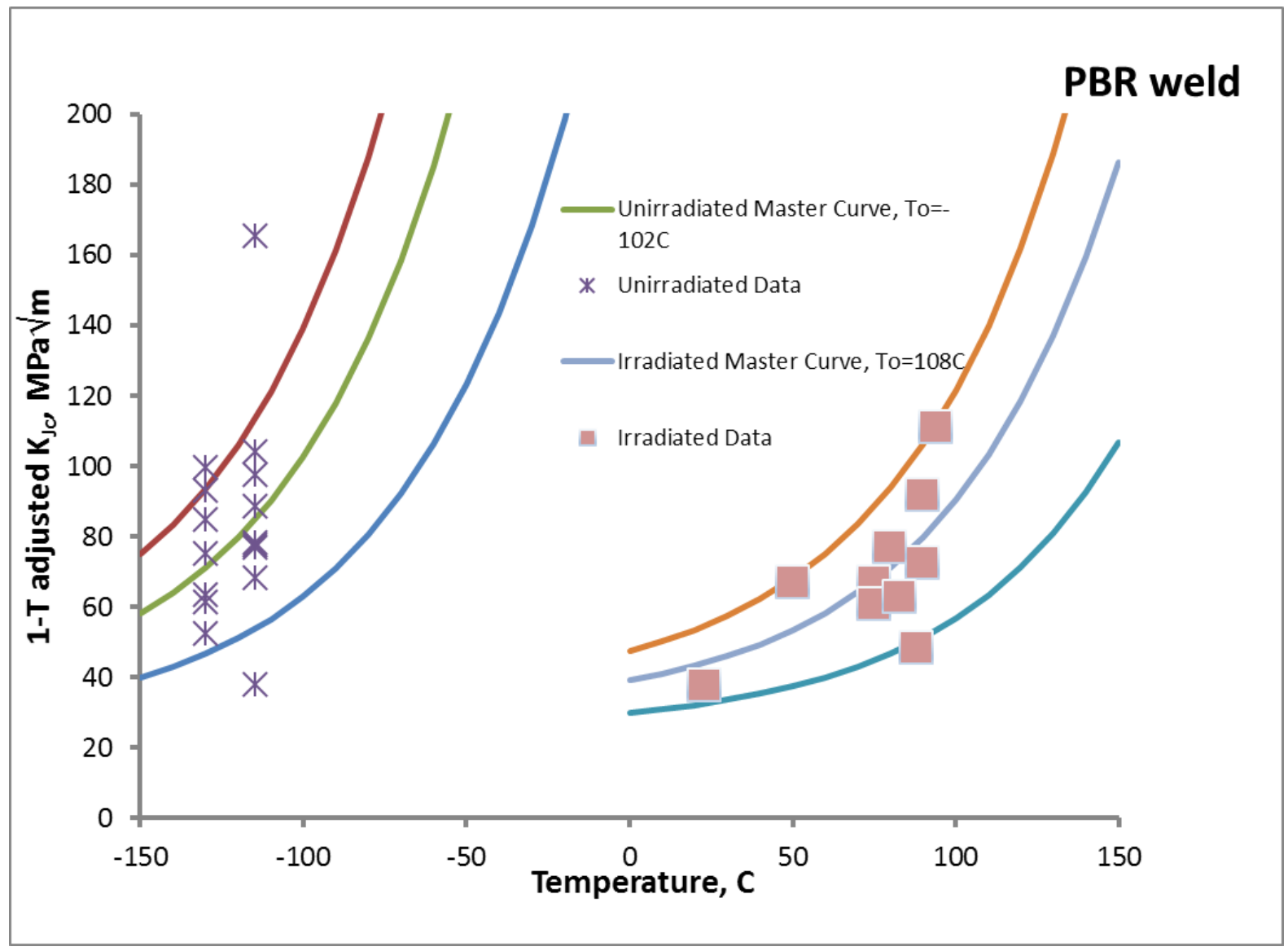

Figure 1. Adjusted fracture toughness data and the master curve for the PBR weld in the unirradiated and irradiated conditions.

\section{SUMMARY}

Fracture toughness characterization of Palisades Nuclear Generating Station reactor pressure vessel weld, PBR, has been performed using DCT specimens. These specimens were irradiated in the UCSB ATR-2 
experiment. Analysis of the data showed very high level of embrittlement of this material. Shift of $\mathrm{T}_{\mathrm{o}}$ is $210^{\circ} \mathrm{C}$.

\section{REFERENCES}

1. Nanstad, R. K., G. R. Odette, and T. Yamamoto, "Progress Report on Disassembly of UCSB ATR-2 Capsule and Revision to Post-Irradiation Plan," ORNL/TM-2014/525, Oak Ridge National Laboratory, September 2014.

2. Nanstad, R. K. and G. R. Odette, "Reactor Pressure Vessel Task of Light Water Reactor Sustainability Program: Milestone Report on Materials and Machining of Specimens for the ATR-2 Experiment," ORNL/LTR-2011/413, Oak Ridge National Laboratory, January 2011.

3. Nanstad, R. K., "Reactor Pressure Vessel Task of Light Water Reactor Sustainability Program: Assessment of High Value Surveillance Materials," ORNL/LTR-2011/172, Oak Ridge National Laboratory, June 2011.

4. Nanstad, R. K., G. R. Odette, T. Yamamoto and M. A. Sokolov, "Post-irradiation Examination Plan for ORNL and University of California Santa Barbara Assessment of UCSB ATR-2 Irradiation Experiment," ORNL/TM-2013/598, Oak Ridge National Laboratory, December 2013.

$5 . \quad$ R. K. Nanstad, G. R. Odette, N. Almirall, J. P. Robertson, W. L. Server, T. Yamamoto, and P. Wells, "Effects of ATR-2 Irradiation to High Fluence on Nine RPV Surveillance Materials", ORNL/TM2017/172, Oak Ridge National Laboratory, December 2016

6. G. R. Odette, et. al., "Update on the High Fluence Advanced Test Reactor - 2 Reactor Pressure Vessel High Fluence Irradiation Project," UCSB ATR-2 2016-1, University of California, Santa Barbara, Santa Barbara, CA, June 30, 2016.

7. $\quad$ "As-Run Thermal Analysis of the UCSB-2 Experiment in the ATR," 2016; ATR NSUF ECAR No. 3218, Project No. 30946.

8. $\quad$ "As-Run Physics Analysis for the UCSB-2 Leadout Experiment in I-22," 2016; ATR NSUF ECAR No. 3219, Project No. 30946.

9. Standard Test Method for Determination of Reference Temperature, To, for Ferritic Steels in the Transition Range, Designation E 1921, Annual Book of ASTM Standards, Vol. 03.01.

10. M.A. Sokolov, X. Chen, R.K. Nanstad, G.R. Odette, T. Yamamoto, P. Wells, "Fracture

Toughness Characterization of Reactor Pressure Alloys from the ATR-2 Experiment", ORNL/TM2017/358, Oak Ridge National Laboratory, July 2017. 